\title{
Reliability and validity of the Korean standard pattern identification for stroke (K-SPI-Stroke) questionnaire
}

\author{
Byoung-Kab Kang, Tae-Yong Park, Ju Ah Lee, Tae-Woong Moon, Mi Mi Ko, Jiae Choi and Myeong Soo Lee*
}

\begin{abstract}
Background: The present study was conducted to examine the reliability and validity of the 'Korean Standard Pattern Identification for Stroke (K-SPI-Stroke)', which was developed and evaluated within the context of traditional Korean medicine (TKM).

Methods: Between September 2006 and December 2010, 2,905 patients from 11 Korean medical hospitals were asked to complete the K-SPI-Stroke questionnaire as a part of project ' Fundamental study for the standardization and objectification of pattern identification in traditional Korean medicine for stroke (SOPI-Stroke). Each patient was independently diagnosed by two TKM physicians from the same site according to one of four patterns, as suggested by the Korea Institute of Oriental Medicine: 1) a Qi deficiency pattern, 2) a Dampness-phlegm pattern, 3) a Yin deficiency pattern, or 4) a Fire-heat pattern. We estimated the internal consistency using Cronbach's a coefficient, the discriminant validity using the means score of patterns, and the predictive validity using the classification accuracy of the K-SPI-Stroke questionnaire.
\end{abstract}

Results: The K-SPI-Stroke questionnaire had satisfactory internal consistency $(a=0.700)$ and validity, with significant differences in the mean of scores among the four patterns. The overall classification accuracy of this questionnaire was $65.2 \%$.

Conclusion: These results suggest that the K-SPI-Stroke questionnaire is a reliable and valid instrument for estimating the severity of the four patterns.

Keywords: Reliability, Validity, Pattern identification, Stroke

\section{Background}

Stroke, the second most common cause of death in Korea, is a considerable burden on Korean society. According to an annual report of the National Health Insurance Corporation in 2009, the estimated cost to treat and manage cerebrovascular diseases totals 920 billion won (approximately 0.87 billion dollars) [1].

Historically, traditional Korean medicine (TKM), which considers- the location, cause, and nature of patients' diseases, has been the major treatment modality in the Korean medical system for properly treating stroke patients.

TKM has a unique diagnostic system called pattern identification (PI), which distinguishes it from modern

\footnotetext{
* Correspondence: mslee@kiom.re.kr

Medical Research Division, Korea Institute of Oriental Medicine, Daejeon,
} Republic of Korea
Western medicine. PI is a process of the overall analysis of clinical data using an integrative approach that addresses the etiology, pathology, and treatment method [2]. This diagnostic system is theoretically well organized and involves the classification of patients into certain categories. However, other medical systems did not recognize the pattern classifications of TKM as a diagnostic system by TKM doctors, which prompted these doctors to study whether they could make the same diagnosis in identical patients (reliability) and whether their diagnoses were accurate (validity). Considering the importance of PI in determining treatment regimens, an accurate questionnaire is warranted.

In the last five years, many TKM doctors have studied the diagnostic validity and reliability of TKM for various health conditions [2-6]. Lee et al. [7] released the Korean Standard 
Pattern Identification for Stroke (K-SPI-Stroke) in 2011, which included the sign and symptoms used by TKM doctors to diagnose patterns of stroke in Korean patients. We evaluated the reliability and validity of the K-SPI-Stroke.

\section{Methods}

\section{Study subjects and data collection}

This study was a community-based multi-center trial. Stroke patients were admitted to 11 TKM hospitals. We enrolled stroke patients within 30 days of the onset of their symptoms as confirmed by imaging diagnosis, such as computerized tomography (CT) or magnetic resonance imaging (MRI). We excluded traumatic strokes, such as subarachnoid, subdural, and epidural hemorrhages. Moreover, we excluded patients who exhibited a blood stasis pattern. Originally, blood stasis was one of the possible patterns, but the number of patterns was changed from four patterns to five pattern in a previous study [7] because blood stasis was dropped due to a small sample size. Informed consent was received from all of the subjects, and PI was performed using the 44 signs and symptoms related to the four patterns. On the same day, to minimize differences between the two diagnoses, patients were independently diagnosed with one of the four patterns using PI by two physicians. The physicians had at least three years of clinical experience with stroke after finishing their regular (six years) education in TKM. The physicians took regular training courses on standard operating procedures (SOP) twice a year. The number of physicians at each site ranged from 2 to 25 , and a total of 105 physicians were included in this study. On the basis of the diagnostic results from the physicians, the patients were classified to have an identical pattern when the two physicians' decisions were in agreement. Over 40 months, 2,905 patients participated in this study (from September 2006 to December 2010). This study was approved by the Institutional Review Boards of the Korea Institute of Oriental Medicine (KIOM) and each of the participating TKM hospitals.

\section{Pattern identification questionnaire}

The K-SPI-Stroke questionnaire was developed in a previous study via a multistage process [8]. First, the signs and symptoms included in the K-SPI-Stroke were selected from the TKM literature, textbooks, and clinical papers by an expert committee organized by the KIOM. Second, a K-SPI-Stroke prototype featuring various signs and symptoms was applied to test the data from recruited patients. The K-SPI-Stroke was then reexamined by a committee of experts and adjusted to maximize its validity. Consequently, the final version of the K-SPI-Stroke included 44 sign and symptom entries (11 Qi deficiency pattern items, 7 Dampness-phlegm pattern items, 7 Yin deficiency pattern items and 19 Fire-heat pattern items) $[7,9,10]$. The severity for each item is graded on the following scale: $1=$ not significant, $2=$ significant and $3=$ very significant. To convert this scale to a dichotomous scoring system, 0 points were assigned for a grade score of 1 , and 1 point was given for each item receiving a graded score of 2 or 3 . The dichotomous scores of each item were summed, and the K-SPI-Stroke score (Qi deficiency pattern score: QDP score, Dampness-phlegm pattern score: DPP score, Yin deficiency pattern score: YDP score, and Fire-heat pattern score: FHP score) was calculated.

\section{Statistical methods}

The internal consistency of the questionnaire was assessed using Cronbach's $\alpha$ coefficient. It has been suggested that

Table 1 Demographic characteristics of patients with stroke

\begin{tabular}{|c|c|c|}
\hline \multirow{2}{*}{$\begin{array}{l}\text { Variables } \\
\text { Age (yrs), mean(SD) }\end{array}$} & \multicolumn{2}{|c|}{ mean (SD), no. (\%) } \\
\hline & $66.98(11.55)$ & \\
\hline \multicolumn{3}{|l|}{ Gender, no. (\%) } \\
\hline Male & 1530 & $52.67 \%$ \\
\hline Female & 1375 & $47.33 \%$ \\
\hline \multicolumn{3}{|l|}{ Drinking history, no. (\%) } \\
\hline No & 1041 & $35.91 \%$ \\
\hline Yes & 1858 & $64.09 \%$ \\
\hline \multicolumn{3}{|l|}{ Smoking history, no. (\%) } \\
\hline No & 862 & $29.74 \%$ \\
\hline Yes & 2036 & $70.26 \%$ \\
\hline Weight (kg), mean(SD) & $57.05(9.62)$ & \\
\hline Height (cm), mean(SD) & $157.92(8.50)$ & \\
\hline \multicolumn{3}{|l|}{ Marriage status, no. (\%) } \\
\hline Single & 62 & $2.16 \%$ \\
\hline Married & 2049 & $71.37 \%$ \\
\hline Divorce & 62 & $2.16 \%$ \\
\hline Widowed & 698 & $24.31 \%$ \\
\hline \multicolumn{3}{|l|}{ Diabetes, no. (\%) } \\
\hline No & 2113 & $73.27 \%$ \\
\hline Yes & 771 & $26.73 \%$ \\
\hline \multicolumn{3}{|l|}{ Hyperlipidemia, no. (\%) } \\
\hline No & 2498 & $87.37 \%$ \\
\hline Yes & 361 & $12.63 \%$ \\
\hline \multicolumn{3}{|l|}{ Hypertension, no. (\%) } \\
\hline No & 1140 & $39.46 \%$ \\
\hline Yes & 1749 & $60.54 \%$ \\
\hline \multicolumn{3}{|c|}{ Anticoagulant treatment, no. (\%) } \\
\hline No & 1913 & $67.86 \%$ \\
\hline Yes & 906 & $32.14 \%$ \\
\hline NIHSS score, mean(SD) & 4.32 (3.78) & \\
\hline
\end{tabular}

SD standard deviation. 
Table 2 Internal consistency (Cronbach's coefficient a) total and within each pattern and mean scores for each item of patterns

\begin{tabular}{|c|c|c|c|c|c|}
\hline Symptoms and Signs & Alpha if item deleted & Qi deficiency & Dampness-phlegm & Yin deficiency & Fire-heat \\
\hline Total & $a=0.700$ & & & & \\
\hline Qi deficiency & & & & & \\
\hline Drowsiness, likes to lie down & 0.696 & $1.18(0.97)$ & $0.99(0.75)$ & $1.03(0.84)$ & $0.93(0.75)$ \\
\hline Feels powerless and lazy & 0.693 & $1.85(0.73)$ & $1.46(0.6)$ & $1.61(0.65)$ & $1.38(0.59$ \\
\hline Looks powerless and lazy & 0.693 & $1.94(0.66)$ & $1.44(0.57)$ & $1.62(0.61)$ & $1.35(0.53)$ \\
\hline Pale complexion & 0.694 & $1(1.05)$ & $0.29(0.61)$ & $0.39(0.7)$ & $0.26(0.54)$ \\
\hline Reluctance to speak & 0.690 & $1.58(0.68)$ & $1.25(0.5)$ & $1.34(0.59)$ & $1.21(0.5)$ \\
\hline Pale tongue & 0.694 & $0.81(1.02)$ & $0.74(0.96)$ & $0.43(0.78)$ & $0.4(0.75)$ \\
\hline Teeth-marked tongue & 0.695 & $0.54(0.88)$ & $0.5(0.8)$ & $0.37(0.66)$ & $0.38(0.67)$ \\
\hline Slow pulse & 0.694 & $0.77(0.98)$ & $0.54(0.82)$ & $0.45(0.71)$ & $0.37(0.67)$ \\
\hline Weak pulse & 0.694 & $1.35(1.04)$ & $0.6(0.87)$ & $0.92(0.97)$ & $0.44(0.74)$ \\
\hline Fine pulse & 0.702 & $1.42(0.6)$ & $1.08(0.36)$ & $1.38(0.57)$ & $1.06(0.35)$ \\
\hline Reversed cold in the extremities & 0.697 & $1.11(0.57)$ & $1.02(0.47)$ & $1.05(0.49)$ & $1(0.39)$ \\
\hline \multicolumn{6}{|l|}{ Dampness-phlegm $a=0.424$} \\
\hline Sallow complexion & 0.705 & $0.58(0.88)$ & $1.2(0.94)$ & $0.6(0.84)$ & $0.45(0.75)$ \\
\hline Dark inferior palpebral & 0.705 & $1.17(0.39)$ & $1.22(0.43)$ & $1.14(0.4)$ & $1.11(0.37)$ \\
\hline Dizziness with nausea & 0.688 & $1.12(0.42)$ & $1.19(0.5)$ & $1.16(0.47)$ & $1.13(0.44)$ \\
\hline White fur on tongue & 0.703 & $1.28(1)$ & $1.36(0.99)$ & $0.92(0.98)$ & $0.91(1.02)$ \\
\hline Enlarged tongue & 0.691 & $0.41(0.76)$ & $0.56(0.83)$ & $0.39(0.67)$ & $0.42(0.72)$ \\
\hline Slippery pulse & 0.706 & $1.2(0.51)$ & $1.75(0.55)$ & $1.24(0.5)$ & $1.4(0.58)$ \\
\hline Heavy & 0.693 & $0.34(0.72)$ & $0.82(1.02)$ & $0.44(0.74)$ & $0.62(0.91)$ \\
\hline \multicolumn{6}{|l|}{ Yin deficiency $a=0.525$} \\
\hline Pale face and red zygomatic-site & 0.686 & $0.19(0.52)$ & $0.25(0.58)$ & $0.8(0.95)$ & $0.34(0.69)$ \\
\hline Dry mouth & 0.690 & $1.54(0.67)$ & $1.45(0.61)$ & $1.78(0.72)$ & $1.6(0.73)$ \\
\hline Dry fur on tongue & 0.689 & $0.47(0.77)$ & $0.56(0.76)$ & $0.99(1.01)$ & $0.84(0.95)$ \\
\hline Bare and red tongue like a mirror & 0.683 & $0.16(0.46)$ & $0.17(0.4)$ & $0.49(0.83)$ & $0.25(0.51)$ \\
\hline Night sweating & 0.696 & $1.17(0.46)$ & $1.16(0.43)$ & $1.3(0.56)$ & $1.21(0.48)$ \\
\hline Tidal fever & 0.696 & $1.05(0.31)$ & $1.05(0.28)$ & $1.19(0.47)$ & $1.1(0.4)$ \\
\hline Thin & 0.690 & $0.37(0.77)$ & $0.28(0.59)$ & $0.66(0.96)$ & $0.48(0.79)$ \\
\hline \multicolumn{6}{|l|}{ Fire-heat $\alpha=0.599$} \\
\hline Vexation and insomnia & 0.689 & $0.42(0.65)$ & $0.47(0.69)$ & $0.65(0.84)$ & $0.66(0.88)$ \\
\hline Reddened complexion & 0.700 & $0.31(0.7)$ & $0.48(0.82)$ & $0.6(0.91)$ & $1.43(1.02)$ \\
\hline Headache like flush & 0.696 & $0.33(0.56)$ & $0.28(0.51)$ & $0.33(0.58)$ & $0.33(0.61)$ \\
\hline Blood-shot eyes & 0.713 & $1.6(0.6)$ & $1.49(0.55)$ & $1.5(0.56)$ & $1.54(0.6)$ \\
\hline Wheezing in the throat with sputum & 0.715 & $1.08(0.54)$ & $1.17(0.64)$ & $1.08(0.63)$ & $1.14(0.64)$ \\
\hline Aphtha or tongue sore & 0.694 & $0.94(0.38)$ & $0.94(0.42)$ & $1(0.43)$ & $1.03(0.38)$ \\
\hline Fetid mouth odor & 0.693 & $1.07(0.5)$ & $1.2(0.56)$ & $1.11(0.54)$ & $1.29(0.63)$ \\
\hline Thirst & 0.694 & $1.32(0.59)$ & $1.3(0.55)$ & $1.45(0.66)$ & $1.51(0.73)$ \\
\hline Red tongue & 0.694 & $0.43(0.81)$ & $0.5(0.82)$ & $1.08(1.04)$ & $1.09(1.05)$ \\
\hline Yellow fur & 0.694 & $0.45(0.83)$ & $0.7(0.94)$ & $0.66(0.89)$ & $1.07(1.07)$ \\
\hline Thick fur & 0.691 & $0.68(0.95)$ & $1.15(1.01)$ & $0.72(0.87)$ & $1.22(1.05)$ \\
\hline Heat vexation in the chest & 0.683 & $0.46(0.7)$ & $0.43(0.68)$ & $0.62(0.82)$ & $0.59(0.87)$ \\
\hline Turbid urine & 0.695 & $1.15(0.6)$ & $1.05(0.66)$ & $1.2(0.58)$ & $1.13(0.7)$ \\
\hline Rapid pulse & 0.694 & $0.48(0.81)$ & $0.76(0.94)$ & $1(1.04)$ & $1.05(1.01)$ \\
\hline
\end{tabular}


Table 2 Internal consistency (Cronbach's coefficient a) total and within each pattern and mean scores for each item of patterns (Continued)

\begin{tabular}{|c|c|c|c|c|c|}
\hline Strong pulse & 0.702 & $0.46(0.8)$ & $0.96(0.98)$ & $0.68(0.91)$ & $1.43(1)$ \\
\hline Surging pulse & 0.702 & $1(0.24)$ & $1.04(0.29)$ & $1.01(0.29)$ & $1.19(0.49)$ \\
\hline Heat vexation and aversion to heat & 0.700 & $1.37(0.6)$ & $1.41(0.58)$ & $1.51(0.66)$ & $1.71(0.73)$ \\
\hline Heat in the palms and soles & 0.695 & $0.94(0.39)$ & $0.98(0.45)$ & $1.08(0.53)$ & $1.11(0.49)$ \\
\hline Vexing heat in the extremities & 0.695 & $0.94(0.4)$ & $0.99(0.46)$ & $0.98(0.43)$ & $1.1(0.5)$ \\
\hline Total & & $40.01(7.97)$ & $40.25(8.45)$ & $41.93(8.61)$ & $42.23(8.78)$ \\
\hline
\end{tabular}

values of $\alpha>0.5$ are acceptable, although ideally the scores should be $>0.7[11,12]$. The K-SPI-Stroke score of each pattern was calculated by summing all of the relevant item scores for each pattern category. As an indication of the discriminant validity, the mean score of the patients' diagnosed pattern should be significantly higher than the other nondiagnosed patterns, indicating the scores' ability to differentiate among the patterns. The underlying hypothesis was that stroke patients would report higher scores for their diagnosed pattern and thus report lower scores for the other nondiagnosed patterns. To test the discriminant validity, which test whether measures that are supposed to be unrelated are in fact unrelated [13], we used a one-way analysis of variance (ANOVA to compare the mean scores of the four patterns. Posteriori comparisons were performed using Scheffé's test. To evaluate the predictive validity, we used a classification accuracy test with a discriminant linear function for the four patterns. Statistical significance was achieved when a P value was less than 0.05. All analyses were performed with SAS version 9.1.3 (SAS Institute, Cary, NC).

\section{Results}

Demographic characteristics of patients with stroke The mean age of the 2,905 subjects was 66.98 (standard deviation, 11.55) years. The numbers of male and female were $1,530(52.67 \%)$ and 1,375 (47.33\%), respectively. Approximately $65 \%$ of the patients had histories of drinking and smoking. Patients with diabetes and hyperlipidemia accounted for $26.73 \%$ and $12.63 \%$ of the population, respectively. The frequency of stroke patients with hypertension $(60.54 \%)$ was higher than the frequency of patients with diabetes or hyperlipidemia. Other variables are also presented in Table 1.

\section{Reliability analysis}

Cronbach's $\alpha$ coefficient was computed to test the internal consistency of the 44 items on the K-SPI-Stroke questionnaire. Cronbach's $\alpha$ was 0.70 for the 44 signs and symptoms, indicating that the K-SPI-Stroke exhibited good internal consistency and the alpha values for the patterns ranged from 0.42 to 0.67 (Table 2).

\section{Validity analysis}

Because we expected to find that the mean scores of each pattern would differ depending on the diagnosed pattern of the patient, we assessed the discriminant validity using an ANOVA for the mean scores of the four patterns. We compared the means of the scores (FHP, DPP, QDP and YDP scores) to determine whether differences could be detected among the four patterns. The mean FHP score for the FHP patients was significantly higher than that for the DPP, QDP and YDP patients. The mean score of patients' diagnosed pattern was significantly higher than the mean scores of the other patterns (Table 3 ).

To evaluate the predictive validity of this study, we used a discriminant analysis to classify the four patterns. The linear discriminant function, which consisted of the 44 items for the four patterns, is not shown. The predictive function that was taken into consideration for the distribution of the patterns and the individual patterns was assessed with the classification rates listed for the whole model. Table 4 shows the classification results for the four patterns. The overall accuracy of the classification of the four patterns was $65.2 \%$, and the

Table 3 Discriminant validity of the four patterns

\begin{tabular}{lcccrr}
\hline & QDP $(\mathbf{n}=\mathbf{6 3 0})$ & DPP $(\mathbf{n}=\mathbf{1}, \mathbf{0 3 7})$ & YDP $(\mathbf{n}=\mathbf{4 0 7})$ & FHP $(\mathbf{n}=\mathbf{8 3 1})$ & \multicolumn{1}{c}{-value } \\
\hline QDP score & $13.55(3.96)^{\mathrm{A}}$ & $9.92(3.44)^{\mathrm{B}}$ & $10.60(3.37)^{\mathrm{B}}$ & $8.78(3.20)^{\mathrm{C}}$ & $<.0001$ \\
DPP score & $6.10(2.13)^{\mathrm{B}}$ & $8.10(2.42)^{\mathrm{A}}$ & $5.88(2.32)^{\mathrm{C}}$ & $6.02(2.27)^{\mathrm{C}}$ & $<.0001$ \\
YDP score & $4.96(1.98)^{\mathrm{B}}$ & $4.92(2.00)^{\mathrm{B}}$ & $7.20(2.51)^{\mathrm{A}}$ & $5.81(2.39)^{\mathrm{B}}$ \\
FHP score & $15.41(3.8)^{\mathrm{C}}$ & $17.32(4.34)^{\mathrm{B}}$ & $18.26(4.18)^{\mathrm{B}}$ & $21.63(4.80)^{\mathrm{A}}$ & $<.0001$ \\
\hline
\end{tabular}

The letters reflect the results from the one-way ANOVA within the same PI scores. Different letters represent a significant a posteriori comparison test between the groups of the $\mathrm{Pl}$.

QDP Qi deficiency pattern, DPP Dampness-phlegm pattern, YDP Yin deficiency pattern, FHP Fire-heat pattern. 
Table 4 Results using the classification of discriminant linear function

\begin{tabular}{|c|c|c|c|c|c|c|}
\hline & & \multicolumn{5}{|c|}{ Classification result $\mathbf{n}(\%)$} \\
\hline & & QDP & DPP & YDP & FHP & Total \\
\hline \multirow[t]{5}{*}{ Physician's diagnosis } & QDP & $404(64.13)$ & $136(21.59)$ & $45(7.14)$ & $45(7.14)$ & $630(21.68)$ \\
\hline & DPP & $95(9.16)$ & $753(72.61)$ & $37(3.57)$ & $152(14.66)$ & $1037(35.70)$ \\
\hline & YDP & $65(15.97)$ & 77 (18.92) & $170(41.77)$ & $95(23.34)$ & $407(14.01)$ \\
\hline & FHP & $39(4.69)$ & $175(21.06)$ & $50(6.02)$ & $567(68.23)$ & $831(28.61)$ \\
\hline & Total & $603(20.76)$ & $1141(39.28)$ & $302(10.4)$ & $859(29.57)$ & $2905(100)$ \\
\hline
\end{tabular}

QDP Qi deficiency pattern, DPP Dampness-phlegm pattern, YDP Yin deficiency pattern, FHP Fire-heat pattern.

individual classification accuracy for QDP, DPP, YDP and FHP was $64.13 \%, 72.61 \%, 41.77 \%$, and $68.23 \%$, respectively.

\section{Discussion}

This study demonstrates that the K-SPI-Stroke questionnaire is a reliable and valid instrument. Reliability and validity are two important factors in designing a questionnaire. Reliability is concerned with the repeatability or reproducibility of the measurements while validity reflects the accuracy of the data and ensures that responses are a true reflection of the issues of interest [14-17]. To test the reliability of the K-SPI-Stroke questionnaire, we evaluated its internal consistency by using Cronbach's $\alpha$, which equals zero when the true score is not measured at all and when the data show only errors or noise; when Cronbach's $\alpha$ equals 1.0, all of the items measure the true score alone without any error contributions.

The K-SPI-Stroke questionnaire had strong internal consistency, with a Cronbach's $\alpha$ of 0.700 for the total signs and symptoms. However, each pattern was unsatisfactory and varied from 0.424 to 0.674 . The poor reliability of the internal consistency in each pattern may suggest that the pattern constructs are not homogenous, or perhaps that the signs and symptoms are not appropriate measures of these constructs for stroke. It is likely that supplementing other patterns of K-SPI-Stroke with additional signs and symptoms, or eliminating poor signs and symptoms, may improve the reliability of the internal consistency for this questionnaire.

Cronbach's $\alpha$ increased to a maximum of 0.715 when "wheezing in throat with sputum" was removed. Although this result implies that "wheezing in throat with sputum" does not measure stroke with the same validity as the other items, this item was not removed because this symptom had little influence on the overall internal consistency of the K-SPI-Stroke questionnaire.

In the analysis of the validity, we used two methods: scores comparison and a classification accuracy test. The mean score of the patients' diagnosed pattern was significantly higher than the mean scores of the other patterns. In other words, the QDP, DPP, YDP and FHP patients reported the highest mean score for the QDP, DPP, YDP and FHP pattern, respectively. Thus, each score was a good reflection of the patient's pathologic pattern. The second method was to compare the classification results with the physicians' diagnoses to show the classification accuracy. The overall classification accuracy of the four patterns was $65.2 \%$, and the classification accuracy of the QDP, DPP, YDP and FHP was $64.13 \%, 72.61 \%$, $41.77 \%$, and $68.23 \%$, respectively.

The YDP score was significantly higher than the scores of the other patterns (Table 2). However, the classification accuracy of the YDP (41.77\%) was lower than that of the other patterns (Table 3). This result indicates that some of the YDP items may not have accurately reflected the YDP pattern. In order words, the K-SPI-Stroke questionnaire does not discriminate YDP among the four patterns because in TKM, YDP simultaneously includes a Heat element of the FHP and a deficiency element of the QDP.

\section{Conclusion}

A 44 items for K-SPI-Stroke was developed, which included 33 items related to signs and 11 items related to symptoms of stroke. The developed K-SPI-Stroke questionnaire had satisfactory reliability $(\alpha=0.700)$, predictive validity (classification accuracy of $65.2 \%$ ) and discriminant validity with significant differences in the means of scores among the patterns. Further studies are warranted to overcome the predictive validity limitation.

\section{Competing interests}

The authors declare that they have no competing interests.

\section{Acknowledgments}

We are grateful to the physicians from the eleven oriental medical hospitals who participated in the study. This study was supported by a grant from the KIOM (K12130).

\section{Authors' contributions}

BKK, TYP and MSL conceived and participated in the study design and coordination and helped to draft the manuscript. JAL, TWM, MMK, and JC participated in the study design and helped to draft the manuscript. All of the authors read and approved the final manuscript. 


\section{References}

1. Social Statistics Office. Statistics on the Cause of Death. In. Seoul, Korea: Korean Statistical Information Service; 2010.

2. Lee SJ, Park JB, Lee HS, Kim KH: Development and validation of Yin-Deficiency Questionnaire. Am J Chin Med 2007, 35:11-20.

3. Park YJ, Park JS, Kim MY, Park YB: Development of a valid and reliable phlegm pattern questionnaire. J Altern Complement Med 2011, 17(9):1-8.

4. Ryu HH, Lee HJ, Kim HG, Kim JY: Reliability and validity of a cold-heat pattern questionnaire for traditional Chinese medicine. J Altern Complementary Med 2010, 6:663-667.

5. Yoo JH, Kim JW, Kim KK, Kim JY, Koh BH, Lee EJ: Sasangin diagnosis questionnaire: test of reliability. J Altern Complement Med 2007, 13:111-122.

6. Kang BK, Moon TW, Lee JA, Park TY, Ko MM, Lee MS: The fundamental study for the standardisation and objectification of pattern identification in traditional Korean medicine for stroke SOPI-Stroke): Development and interobserver agreement of the Korean standard pattern identification for stroke (K-SPI-Stroke) tool. Eur J Intergrative Med 2012, in press: doi:10.1016/j.eujim.2012.01.002.

7. Lee JA, Lee JS, Kang BK, Go MM, Moon TW, Cho KH, Bang OS: Report on the Korean standard pattern identifications for stroke-iii. Korean J Oriental Int 2011, 32:232-242.

8. Park TY, Lee JA, Cha MH, Kang BK, Moon TW, Choi TY, Ko MM, Choi JA, Lim JH, Lee HY et al: The Fundamental Study for the Standardization and Objectification of Pattern Identification in Traditional Korean Medicine for Stroke (SOPI-Stroke): An overview of phase I. Eur J Intergrative Med 2012, in press: doi:10.1016/j.eujim.2012.01.003.

9. Go HY, Kim JK, Kang BK, Kim BY, Ko MM, Kang KW, Seol IC, Lee I, Jo HK, Yu BC et al: Report on the Korean standard differentiation of the symptoms and signs for the stroke-2. Korean J Orient Physiol Pathol 2006, 20:1789-1791.

10. Kim J, Seol IC, Lee I, Jo HK, Yu BC, Choi SM: Report on the Korean standard differentiation of the symptoms and signs for the stroke-1. Korean J Oriental Physiol Pathol 2006, 20:229-234.

11. Nunnaly JC, Bernstein IH: Psychometric Theory. New York: McGraw-Hill; 1994.

12. Helmstadter GC: Principles of Psychological Measurement. New York: Appleteon-Century-Crofts; 1964.

13. Campbell DT, Fiske DW: Convergent and discriminat validation by the multitrait-multimethod matrix. Psychol Bull 1959, 59:81-105.

14. Smith F: Survey research: Instruments, validity and reliability, Research Methods in Pharmacy Practice. London: Pharmaceutical Press; 2002.

15. Chen RQ, Cao KJ, Lam TH, Wong CM: Symptom characteristics of kidneyYin deficiency and kidney-yang deficiency in Hong Kong Chinese midlife women. J Altern Complement Med 2008, 14(5):457-460.

16. Park JS, Kim MY, Park YJ: Preliminary study on pattern questionnaire for damum patterns. J Korean Inst Orient Med Diagn 2006, 10(1):55-63.

17. Park JS, Yang DH, Kim MY, Lee SC, Park YJ: Development of questionnaire for Damum patternization. J Korean Inst Orient Med Diagn 2006, 10(1):64-67.

doi:10.1186/1472-6882-12-55

Cite this article as: Kang et al: Reliability and validity of the 315 Korean standard pattern identification for stroke (K-SPI-Stroke) 316

questionnaire. BMC Complementary and Alternative Medicine 2012, 12:55.

\section{Submit your next manuscript to BioMed Central and take full advantage of:}

- Convenient online submission

- Thorough peer review

- No space constraints or color figure charges

- Immediate publication on acceptance

- Inclusion in PubMed, CAS, Scopus and Google Scholar

- Research which is freely available for redistribution

Submit your manuscript at www.biomedcentral.com/submit
C BioMed Central 